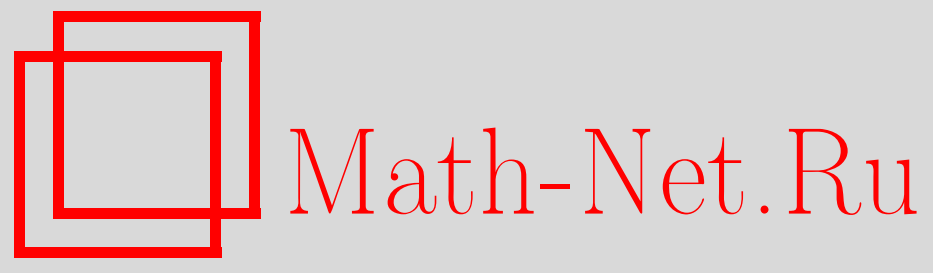

В. П. Радченко, М. Н. Саушкин, Памяти Олега Александровича Репина, Вестн. Сам. гос. техн. ун-та. Сер. Физ.-мат. науки, 2018, номер 3, 401406

DOI: https://doi.org/10.14498/vsgtu1649

Использование Общероссийского математического портала MathNet.Ru подразумевает, что вы прочитали и согласны с пользовательским соглашением

http: //www . mathnet.ru/rus/agreement

Параметры загрузки:

IP : 54.224 .187 .69

26 апреля 2023 г., 14:47:14

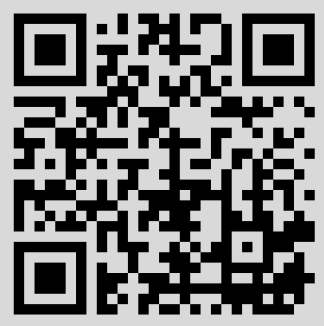


Вестн. Сам. гос. техн. ун-та. Сер. Физ.-мат. науки. 2018. Т. 22, № 3. С. $401-406$ ISSN: 2310-7081 (online), 1991-8615 (print)

\section{Памяти Олега Александровича Репина}

\section{В. П. Радченко, М. Н. Саушкин}

Самарский государственный технический университет,

Россия, 443100, Самара, ул. Молодогвардейская, 244.

4 августа 2018 г. на 72 году жизни после тяжелой болезни скончался наш коллега, член редколлегии нашего журнала доктор физикоматематических наук, профессор Олег Александрович Репин.

Олег Александрович был крупным ученым в области теории дифференциальных уравнений с частными производными. Он вел активную научную деятельность, поддерживал интенсивные научные контакты с ведущими научными центрами России и был хорошо известен за рубежом.

В настоящей биографической заметке описывается его научно-педагогическая деятельность, приводятся сведения о его достижениях и наградах, а также список основных публикаций за последние пять лет.

Публикация онлайн: 29 сентября 2018 г.

Олег Александрович Репин родился в 1946 году в Тамбовской области (Бондарский район, село Прибытки) в семье служащего. Его увлечение математикой началось еще в школьные годы: он неоднократно становился призером областных математических олимпиад. В 1964 году он окончил с серебряной медалью среднюю школу и поступил в Тамбовский государственный педагогический институт (ТГПИ).

Исследовательская деятельность заинтересовала Олега Александровича еще в студенческие годы. Его научная работа, посвященная применению математических методов в экономике, привлекла внимание специалистов, и он получил приглашение работать на кафедре политической экономии. В 1968 году после окончания с отличием физико-математического факультета ТГПИ О. А. Репин начал свою трудовую деятельность в качестве инженера-программиста-математика на вычислительном центре металлургического завода им. Ленина г. Куйбышева.

Однако стремление заниматься наукой было столь сильным, что, несмотря на хороший по тем временам заработок и перспективу карьерного роста, Олег Александрович в 1970 году перешел в Куйбышевский плановый институт (ныне Самарский государственный экономический университет - СГЭУ), где проработал почти 50 лет. Он начал свою работу в университете на ка-

\section{Personalia}

(2) (9) Контент публикуется на условиях лицензии Creative Commons Attribution 4.0 International (https://creativecommons .org/licenses/by/4.0/deed.ru)

\section{Образец для цитирования}

Радченко В. П., Саушкин М. Н. Памяти Олега Александровича Репина // Вестн. Сам. гос. техн. ун-та. Сер. Физ.-мат. науки, 2018. Т. 22, № 3. С. 401-406. doi: $10.14498 /$ vsgtu1649. 
федре высшей математики. Именно здесь им были написаны первые работы по математике в области теории дифференциальных уравнений с частными производными. В 1979 году О. А. Репин защитил диссертацию на соискание ученой степени кандидата физико-математических наук, а в 1984 году ему было присвоено ученое звание доцента.

С 1996 года Олег Александрович возглавлял кафедру математической статистики и эконометрики СГЭУ. В 1998 году он защитил диссертацию на соискание ученой степени доктора физико-математических наук на тему «Краевые задачи для уравнений гиперболического и смешанного типа и дробное интегро-дифференцирование», и в 2002 году ему было присвоено ученое звание профессора. В это время в работах О. А. Репина определяется еще одно научное направление, связанное с применением математико-статистических методов в экономических исследованиях.

Все эти годы Олег Александрович вел активную научную деятельность. Он поддерживал интенсивные научные контакты с ведущими научными центрами России: входил в состав ряда оргкомитетов международных и всероссийских научных конференций, выступал с докладами на симпозиумах и конференциях в России и за рубежом.

Высок авторитет профессора О. А. Репина и в международном сообществе ученых-математиков, специалистов в области дифференциальных уравнений. Он является автором более 270 научных работ. Его труды опубликованы в ведущих российских математических журналах и зарубежных изданиях (в Белоруссии, Украине, Узбекистане, Таджикистане, Болгарии, Чехии, США, Японии, Южной Корее, Великобритании).

Реализация оригинальных идей и результатов научных исследований была им продолжена, в том числе, и в Самарском государственном техническом университете, где с 1999 года он работал по совместительству профессором на кафедре «Прикладная математика и информатика» и осуществлял руководство аспирантами по специальности 01.01.02 «Дифференциальные уравнения».

Под руководством О. А. Репина подготовили и защитили кандидатские диссертации 14 аспирантов.

О. А. Репин являлся членом диссертационных советов по защите докторских и кандидатских диссертаций при СГЭУ по специальности «Бухгалтерский учет, статистика» при Самарском государственном университете по специальности «Математическое моделирование, численные методы и комплексы программ». Олег Александрович неоднократно выступал в качестве официального оппонента по защите докторских и кандидатских диссертаций в различных вузах, в том числе в МГУ им. М. В. Ломоносова, в Институте математики им. А. Джураева АН Республики Таджикистан и др. О. А. Репин являлся рецензентом научных статей в центральных российских журналах: «Известия высших учебных заведений. Математика», «Дифференциальные уравнения», «Сибирский математический журнал» и многих других.

О. А. Репин входил в состав редколлегий научных журналов: «Вестник Самарского государственного экономического университета», «Вестник молодых ученых Самарского государственного экономического университета», «Вестник Самарского государственного технического университета. Сер. Физико-математические науки».

Олег Александрович Репин - опытный преподаватель, умел интересно и доходчиво донести до слушателя весьма сложные понятия и методы теории вероятностей, математической статистики, эконометрики. Им в соавторстве 
подготовлен ряд учебных пособий по данным дисциплинам, в том числе с грифом УМО и грифом Министерства. О. А. Репин неоднократно выполнял обязанности председателя государственной аттестационной комиссии по специальности «Математика» в Кабардино-Балкарском государственном университете им. Х. М. Бербекова, Самарском государственном университете.

Под руководством О. А. Репина преподаватели кафедры математической статистики и эконометрики СГЭУ вели активную научную и учебно-методическую работу. Мудрый и требовательный руководитель, человек необыкновенной работоспособности, всегда готовый помочь и поддержать, Олег Александрович сумел создать в коллективе атмосферу творческой работы и доброжелательных отношений.

Олег Александрович Репин был награжден нагрудным знаком «Почетный работник высшего профессионального образования Российской Федерации».

Он до последнего времени вёл активный образ жизни, был полон идеями и реализовал их, публикуясь в ведущих журналах, специализирующихся по теории дифференциальных уравнений и по другим научным направлениям. Уровень научных исследований и широту его интересов можно оценить хотя бы по его публикациям за последние 5 лет, которые приводятся ниже.

Для сотрудников и членов редколлегии нашего журнала, а также учёных, преподавателей, студентов, знавших его и общавшихся с ним, Олег Александрович останется в памяти как образец Учёного, Педагога, Гражданина, Человека. . .

\section{Избранные труды О. А. Репина за последние 5 лет}

1. О. А. Репин, Об одной задаче для уравнения смешанного типа с дробной производной // Изв. вузов. Матем., 2018. № 8. С. 46-51; O. A. Repin, On a Problem for a Mixed-Type Equation With Fractional Derivative// Russian Math. (Iz. VUZ), 2018. vol. 62, no. 8. pp. 3842. doi : $10.3103 / \mathrm{S} 1066369 \mathrm{X} 18080066$.

2. О. А. Репин, Краевая задача с операторами М. Сайго для уравнения смешанного типа с дробной производной // Изв. вузов. Матем., 2018. № 1. С. 81-86; О. A. Repin, Boundary-Value Problem With Saigo Operators for Mixed Type Equation With Fractional Derivative // Russian Math. (Iz. VUZ), 2018. vol.62, no. 1. pp. 70-75. doi: 10.3103/ S1066369X18010103.

3. О. А. Репин, Е. И. Суханова, Л. К. Ширяева, Математика для экономистов. Теория вероятностей и математическая статистика. Самара: СГЭУ, 2017.

4. О. А. Репин, С. К. Кумыкова, Об одной задаче с обобщенными операторами дробного дифференцирования для вырождающегося внутри области гиперболического уравнения // Диффер. уравн., 2017. Т. 53, № 8. С. 1074-1082; O. A. Repin, S. K. Kumykova, Problem with generalized fractional differentiation operators for a hyperbolic equation degenerating in the interior of the domain // Differ. Equ., 2017. vol.53, no. 8. pp. 1045-1053. doi : 10.1134/S0012266117080092.

5. О. А. Репин, С. К. Кумыкова, Нелокальная задача для вырождающегося гиперболического уравнения // Изв. вузов. Матем., 2017. № 7. C. 50-56; O. A. Repin, S. K. Kumykova, A nonlocal problem for degenerate hyperbolic equation // Russian Math. (Iz. VUZ), 2017. vol. 61, no. 7. pp. 43-48. doi: 10.3103/S1066369X17070064.

6. О. А. Репин, С. К. Кумыкова, Задача с операторами дробного дифференцирования в краевом условии для уравнения смешанного типа // Изв. вузов. Матем., 2017. № 4 . C. 43-49; O. A. Repin, S. K. Kumykova, A problem with operators of fractional differentiation in boundary condition for mixed-type equation // Russian Math. (Iz. VUZ), 2017. vol. 61, no. 4. pp. 35-40. doi : 10.3103/S1066369X17040065.

7. О. А. Репин, Об одной задаче со смещением для уравнения смешанного типа с двумя линиями вырождения // Изв. вузов. Матем., 2017. №1. С. 53-59; О. A. Repin, On a 
problem with shift for mixed type equation with two degeneration lines // Russian Math. (Iz. VUZ), 2017. vol.61, no. 1. pp. 47-52. doi: 10.3103/S1066369X17010066.

8. О. А. Репин, Задача с операторами Сайго для вырождающегося внутри области гиперболического уравнения // Вестн. Сам. гос. техн. ун-та. Сер. Физ.-мат. науки, 2017. T. 21, № 3. C. 473-480. doi : 10.14498/vsgtu1556.

9. О. А. Репин, Об одной краевой задаче с операторами Сайго для уравнения смешанного типа // Вестн. Сам. гос. техн. ун-та. Сер. Физ.-мат. науки, 2017. Т. 21, № 2. С. 271277. doi : 10.14498/vsgtu1540.

10. O. A. Repin, S. K. Kumykova, A boundary-value problem for the equation of mixed type with generalized operators of fractional differentiation in the boundary conditions // J. Appl. Anal., 2016. vol. 22, no. 1. pp. 27-36. doi : 10.1515/jaа-2016-0003.

11. О. А. Репин, А. А. Фролов, Об одной краевой задаче для уравнения смешанного типа с частной дробной производной Римана-Лиувилля // Диффер. уравн., 2016. Т. 52, № 10. C. 1436-1440; O. A. Repin, A. A. Frolov, On a boundary value problem for an equation of mixed type with a Riemann-Liouville fractional partial derivative// Differ. Equ., 2016. vol. 52, no. 10. pp. 1384-1388. doi: 10.1134/S0012266116100165.

12. О. А. Репин, С. К. Кумыкова, О разрешимости нелокальной задачи для одного уравнения гиперболического типа второго рода // Изв. вузов. Матем., 2016. № 9. С. 51-58; O. A. Repin, S. K. Kumykova, On the solvability of a nonlocal problem for a hyperbolic equation of the second kind// Russian Math. (Iz. VUZ), 2016. vol.60, no. 9. pp. 46-52. doi : $10.3103 / \mathrm{S} 1066369 \mathrm{X} 1609005 \mathrm{X}$.

13. О. А. Репин, А. В. Тарасенко, Об одной задаче для уравнения смешанного типа с частной дробной производной Римана-Лиувилля // Вестн. Сам. гос. техн. ун-та. Сер. Физ.-мат. науки, 2016. Т. 20, № 4. С. 636-643. doi: 10.14498/vsgtu1516.

14. О. А. Репин, С. К. Кумыкова, Внутреннекраевая задача с операторами РиманаЛиувилля для уравнения смешанного типа третьего порядка // Becmн. Сам. гос. техн. ун-та. Сер. Физ.-мат. науки, 2016. Т. 20, № 1. С. 43-53. doi: 10.14498/vsgtu1461.

15. О. А. Репин, С. К. Кумыкова, Об одной нелокальной задаче для уравнения смешанного типа третьего порядка с кратными характеристиками// Диффер. уравн., 2015. T. 51, №6. C. 755-763; On a nonlocal problem for a third-order equation of mixed type with multiple characteristics // Differ. Equ., 2015. vol.51, no.6. pp. 767-775. doi: 10.1134/S0012266115060075.

16. О. А. Репин, С. К. Кумыкова, Краевая задача с операторами Сайго для уравнения смешанного типа третьего порядка с кратными характеристиками // Изв. вузов. Маmeм., 2015. № 7. C. 49-57; O. A. Repin, S. K. Kumykova, Boundary-value problem with saigo operators for mixed type equation of the third order with multiple characteristics // Russian Math. (Iz. VUZ), 2015. vol.59, no. 7. pp. 44-51. doi: 10.3103/S1066369X15070051.

17. О. А. Репин, С. К. Кумыкова, Нелокальная задача с обобщенными операторами дробного дифференцирования для уравнения смешанного типа в неограниченной области // Изв. вузов. Матем., 2015. № 4. С. 60-64; O. A. Repin, S. K. Kumykova, A nonlocal problem with generalized fractional differential operators for a mixed-type equation in an unbounded domain // Russian Math. (Iz. VUZ), 2015. vol.59, no.4. pp. 50-53. doi : $10.3103 / \mathrm{S} 1066369 \times 15040076$.

18. О. А. Репин, Краевая задача для дифференциального уравнения с частной дробной производной Римана-Лиувилля // Убимск. матем. журн., 2015. Т. 7, № 3. С. 70-75;

O. A. Repin, Boundary value problem for partial differential equation with fractional Riemann-Liouville derivative// Ufa Math. J., 2015. vol.7, no. 3. pp. 67-72. doi: 10.13108/ 2015-7-3-67.

19. О. А. Репин, А. В. Тарасенко, Нелокальная задача для уравнения с частной производной дробного порядка // Вестн. Сам. гос. техн. ун-та. Сер. Физ.-мат. науки, 2015. T. 19, № 1. C. 78-86. doi : 10.14498/vsgtu1398.

20. О. А. Репин, Е. Г. Репина, Динамические изменения и кластерный анализ в статическом исследовании деятельности микрофинансовых организаций РФ // Вестник Самарского государственного экономического университета, 2015. № 1(123). С. 74-79. 
21. О. А. Репин, С. К. Кумыкова, Нелокальная задача для уравнения смешанного типа в области, эллиптическая часть которой полуполоса // Диффер. уравн., 2014. Т. 50, № 6. C. 807-816; O. A. Repin, S. K. Kumykova, Nonlocal problem for an equation of mixed type in a domain whose elliptic part is a half-strip // Differ. Equ., 2014. vol. 50, no. 6. pp. 805-814. doi : 10.1134/S0012266114060081.

22. О. А. Репин, С. К. Кумыкова, Нелокальная задача с дробными производными для уравнения смешанного типа // Изв. вузов. Матем., 2014. № 8. С. 79-85; O. A. Repin, S. K. Kumykova, A nonlocal problem with fractional derivatives for the mixed type equation// Russian Math. (Iz. VUZ), 2014. vol.58, no.8. pp. 65-70. doi: 10.3103/ S1066369X14080088.

23. О. А. Репин, С. К. Кумыкова, Об одном классе нелокальных задач для гиперболического уравнения с вырождением типа и порядка // Вестн. Сам. гос. техн. ун-та. Сер. Физ.-мат. науки, 2014. №4(37). С. 22-32. doi: 10.14498/vsgtu1348.

24. О. А. Репин, Задача со смещением для одного уравнения с частной дробной производной // Вестн. Сам. гос. техн. ун-та. Сер. Физ.-мат. науки, 2014. №2(35). С. 22-32. doi : $10.14498 /$ vsgtu1318.

25. О. А. Репин, С. К. Кумыкова, Задача со смещением для вырождающегося внутри области гиперболического уравнения // Вестн. Сам. гос. техн. ун-та. Сер. Физ.-мат. науки, 2014. T.1(34). С. 37-47. doi: 10.14498/vsgtu1280.

26. О. А. Репин, С. К. Кумыкова, Задача с обобщенными операторами дробного дифференцирования для уравнения Бицадзе-Лыкова // Доклады Адыгской (Черкесской) Международной академии наук, 2014. Т. 16, №1. С. 24-32.

27. О. А. Репин, С. К. Кумыкова, Внутреннекраевая задача с операторами Сайго для уравнения Геллерстедта // Диффер. уравн., 2013. Т. 49, №10. С. 1340-1349; O. A. Repin, S. K. Kumykova, Interior-boundary value problem with saigo operators for the Gellerstedt equation// Differ. Equ., 2013. vol.49, no.10. pp. 1307-1316. doi: 10.3103/ S1066369X13080069.

28. О. А. Репин, С. К. Кумыкова, Нелокальная задача для уравнения смешанного типа, порядок которого вырождается вдоль линии изменения типа // Изв. вузов. Матем., 2013. № 8. C. 57-65; O. A. Repin, S. K. Kumykova, A nonlocal problem for a mixed-type equation whose order degenerates along the line of change of type// Russian Math. (Iz. VUZ), 2013. vol. 57, no. 8. pp. 49-56. doi: 10.3103/S1066369X13080069.

29. О. А. Репин, С. К. Кумыкова, О задаче с обобщёнными операторами дробного дифференцирования для уравнения смешанного типа с двумя линиями вырождения // Вестн. Сам. гос. техн. ун-та. Сер. Физ.-мат. науки, 2013. №1(30). С. 150-158. doi : 10.14498/vsgtu1141.

30. О. А. Репин, С. К. Кумыкова, Задача с обобщенными операторами дробного интегродифференцирования произвольного порядка // Изв. вузов. Матем., 2012. № 12. С. 5971 ; O. A. Repin, S. K. Kumykova, A problem with generalized fractional integrodifferentiation operators of arbitrary order // Russian Math. (Iz. VUZ), 2012. vol. 56, no. 12. pp. 50-60. doi : 10.3103/S1066369X12120067.

31. О. А. Репин, С. К. Кумыкова, Задача со смещением для уравнения третьего порядка с разрывными коэффициентами // Вестн. Сам. гос. техн. ун-та. Сер. Физ.-мат. науки, 2012. № 4(29). C. 17-25. doi: 10.14498/vsgtu1123.

32. О. А. Репин, С. К. Кумыкова, О задаче с обобщенными операторами дробного дифференцирования для вырождающегося внутри области гиперболического уравнения // Вестн. СамГУ. Естественнонаучн. сер., 2012. № 9(100). С. 52-60.

33. О. А. Репин, Е. И. Суханова, Л. К. Ширяева, Задачи всероссийских студенческих олимпиад по теории вероятностей и математической статистики. СПб.: Лань, 2011.

\section{В. П. Радченко, М. Н. Саушкин}

Используемые материалы. В заметке были использованы материалы и фотография из архива семьи Репиных, предоставленные Е. Г. Репиной. 
Vestn. Samar. Gos. Tekhn. Univ., Ser. Fiz.-Mat. Nauki

[J. Samara State Tech. Univ., Ser. Phys. Math. Sci.], 2018, vol. 22, no. 3, pp. 401-406

ISSN: 2310-7081 (online), 1991-8615 (print)

doi) http://doi.org/10.14498/vsgtu1649

\section{In memory of Prof. Oleg A. Repin}

\section{P. Padchenko, M. N. Saushkin}

Samara State Technical University,

244, Molodogvardeyskaya st., Samara, 443100, Russian Federation.

Oleg A. Repin, age 71, our colleague, editorial board member of the Journal, Professor, Doctor habilitated of Physical and Mathematical Sciences, passed away on August 4th, 2018, after a long battle with serious disease.

Oleg A. Repin was a leading scientist from the field of the theory of partial differential equations. He performed the ambitious scientific activities, kept in touch with the top scientific centers in Russia and was well known abroad.

In this biographical background we discuss the scientific and educational work of Prof. Oleg A. Repin, give an information on his achievements and awards and a list of his main publications for the last five years.

First online: $29^{\text {th }}$ September, 2018

\section{Personalia}

() (1) The content is published under the terms of the Creative Commons Attribution 4.0 International License (http://creativecommons.org/licenses/by/4.0/)

Please cite this article in press as:

Radchenko V. P., Sa ushkin M. N. In memory of Prof. Oleg A. Repin, Vestn. Samar. Gos. Tekhn. Univ., Ser. Fiz.-Mat. Nauki [J. Samara State Tech. Univ., Ser. Phys. Math. Sci.], 2018, vol. 22, no. 3, pp. 401-406. doi: 10.14498/vsgtu1649 (In Russian). 